\title{
Los acuerdos de refinanciación en las cooperativas
}

(Refinancing agreements in cooperatives)

\author{
Blanca Torrubia Chalmeta ${ }^{1}$ \\ Universitat Oberta de Catalunya (España)
}

Sumario: I. Contextualización. II. Cooperativas y crisis. III. Cooperativas y homologación de los acuerdos de refinanciación. III. 1. El papel de las entidades financieras en las refinanciaciones. III. 2. Efectos y extensión de la homologación. III. 3. Acuerdos de refinanciación celebrados por cooperativas. III. 4. Consideraciones a propósito de los acuerdos de refinanciación celebrados por cooperativas IV. Conclusiones. V. Bibliografía.

Summary: I. Contextualization. II. Cooperatives and crises. III. Cooperatives and judicial approval of refinancing agreements. 1 . The role of financial institutions in refinancing. 2. Effects and extension of approval. 3. Refinancing agreements concluded by cooperatives. 4. Considerations regarding refinancing agreements concluded by cooperatives IV. Conclusions. V. Bibliography.

Resumen: Las últimas reformas de la Ley concursal se han sucedido sin tiempo de valorar los efectos de las anteriores. Resulta así difícil extraer conclusiones fiables cuando se observa un determinado fenómeno, como es el caso del que analizaremos en este trabajo: las cooperativas han comenzado a acudir a la figura del acuerdo de refinanciación, como vía para superar su crisis, en el momento en que las sociedades capitalistas están abandonando su empleo. En el presente artículo, partiendo del marco normativo de los acuerdos de refinanciación, de sus efectos y del comportamiento de las cooperativas ante la crisis, se quiere hacer una valoración de este fenómeno. Para ello, se tendrá en cuenta el contenido de los acuerdos que las cooperativas han realizado y se han homologado judicialmente.

Palabras clave: Cooperativas, acuerdos de refinanciación, homologación judicial.

Abstract: The latest reforms of the Spanish Insolvency Law have come one after the other, without time to evaluate the impact of previous ones. It is thus difficult to draw reliable conclusions when a certain phenomenon is ob-

1 Profesora agregada de Derecho mercantil. E-mail: btorrubia@uoc.edu. 
served, as is the case we will analyze in this work: Cooperatives have begun to resort to the figure of the refinancing agreements, as a way to overcome its crisis, when capitalist societies are abandoning their usage. This article, based on the regulatory framework of refinancing agreements and their effects and the behavior of cooperatives in the face of the crisis seeks to evaluate this phenomenon. For this, the content of the negotiations that have been carried out and judicial approved will be taken into account.

Keywords: Cooperatives, refinancing agreements, judicial approval. 


\section{Contextualización}

Las cooperativas, en cuanto sociedades de base mutualista, dirigen su actividad a la satisfacción de las necesidades de los socios, no a la obtención de beneficio en el mercado. La Ley estatal 27/1999, de 16 de julio, de Cooperativas (LCoop), cuya última reforma se ha realizado por la Ley 5/2015, de 27 de abril, de fomento de la financiación empresarial², define la cooperativa como "sociedad constituida por personas que se asocian, en régimen de libre adhesión y baja voluntaria, para la realización de actividades empresariales, encaminadas a satisfacer sus necesidades y aspiraciones económicas y sociales, con estructura y funcionamiento democrático, conforme a los principios formulados por la alianza cooperativa internacional $^{3}$, en los términos resultantes de la presente Ley» (art. 1.1 LCoop) ${ }^{4}$.

2 La Ley 5/2015 traslada, de la Asamblea General, al Consejo Rector la competencia para acordar, salvo disposición contraria en los Estatutos, la emisión de obligaciones y otras formas de financiación mediante emisión de valores negociables, siempre y cuando no se trate de títulos participativos o participaciones especiales, cuya competencia está atribuida a la Asamblea General. El régimen aplicable a las emisiones de obligaciones se contiene en la D.A.5. a. a) El importe total tendrá como límite máximo el capital desembolsado, b) No se aplica este límite si la emisión está garantizada con hipoteca, con prenda de valores, con garantía pública o con aval solidario de entidad de Crédito, c) Se aplica supletoriamente, el título XI de la Ley de Sociedades de Capital. Un estudio de los aspectos problemáticos del órgano de administración en la cooperativa puede verse en Gadea, E. «Configuración general de la estructura orgánica de las sociedades cooperativas: referencia a los aspectos del órgano de administración que necesitan una urgente reforma». Revista crítica de derecho inmobiliario, N. ${ }^{\circ} 755,2016$, págs. 1283-1314.

3 La Alianza Cooperativa Internacional, con sede en Ginebra, es una organización no gubernamental, independiente. Fundada en Londres en 1895, tiene como misión promover y salvaguardar los valores y principios cooperativos. La Alianza representa directamente a 700 millones de personas a través de sus, aproximadamente, 300 miembros de 100 países. En 1995, la Alianza adoptó la Declaración sobre la Identidad Cooperativa, que recoge la definición de cooperativa, los valores de las cooperativas y siete principios cooperativos. La cooperativa se define como "asociación autónoma de personas que se han unido de forma voluntaria para satisfacer sus necesidades y aspiraciones económicas, sociales y culturales en común mediante una empresa de propiedad conjunta y de gestión democrática». Los valores cooperativos son la autoayuda, auto-responsabilidad, democracia, igualdad, equidad y solidaridad. Además, sus miembros cooperativos creen en los valores éticos de honestidad, actitud receptiva, responsabilidad social y respeto hacia los demás. Los principios cooperativos son las directrices a través de las cuales las cooperativas ponen en práctica sus valores, y son: 1) Asociación voluntaria y abierta, 2) Control democrático de los miembros, 3) Participación económica de los socios, 4) Autonomía e independencia, 5) Educación, formación e información, 6) Cooperación entre cooperativas, y 7) Sentimiento de comunidad. Sitio oficial de la $\mathrm{ACl}$ e información en: https://ica.coop/es/node/5.

4 Son muchos los estudios sobre la cooperativa y su caracterización vid. por ejemplo:

Atxabal, A. «La democracia como valor identitario de la cooperativa» Cooperativismo e economía social, N. ${ }^{\circ}$ 37, 2014-2015, págs. 89-114. 
Ahora bien, ni la ausencia de ánimo de lucro, ni el capital variable - como resultado de la posibilidad que tienen los socios cooperativistas de abandonar la sociedad con restitución de sus aportaciones dinerarias-, han impedido su calificación como sociedades mercantiles y la consiguiente sujeción al estatuto jurídico del empresario ${ }^{5}$. Así, tanto la ley estatal de cooperativas, como las diferentes leyes autonómicas, a excepción de la madrileña, riojana y valenciana, recogen expresamente su mercantilidad 6 .

Divar, J. Régimen jurídico de las Sociedades Cooperativas, Universidad de Deusto, (1987).

Gadea, E. Derecho de las cooperativas, Universidad de Deusto, 2001; «Estudio sobre el Concepto de Cooperativa: referencia a los Principios Cooperativos y a su discutida vigencia», Jado: boletín de la Academia Vasca de Derecho, N. ${ }^{\circ}$ 17, 2009, págs. 165-185; «Delimitación del concepto de cooperativa: de los principios cooperativos a la responsabilidad social corporativa», CIRIEC - España. Revista jurídica de economía social y cooperativa, N. ${ }^{\circ}$ 23, 2012, págs. 37-58, Gadea, E., Atxabal, A. Izquierdo, M. E. (Coord.) Las cooperativas como alternativa económica, una visión de México y España, Dykinson, 2014.

Martínez Charterina, A. «Sobre el principio de cooperación entre cooperativas en la actualidad» Boletín de la Asociación Internacional de Derecho Cooperativo N. ${ }^{\circ}$ 46, 2012 (Ejemplar dedicado a: Las cooperativas construyen un mundo mejor), págs. 133-146.

5 Nos remitimos a la doctrina mencionada en la nota anterior.

6 El régimen legal de las cooperativas se integra por la norma estatal (LCoop) y la normativa autonómica recogida en las siguientes leyes:

1) Ley 4/1993, de 24 de junio, de Cooperativas de Euskadi y Ley 1/2000, de 29 de junio, de modificación de la Ley de Cooperativas de Euskadi. Ley 8/2006, de 1 de diciembre, de segunda modificacion de la ley de Cooperativas de Euskadi. Ley 6/2008, de 25 de junio, de la Sociedad Cooperativa Pequeña de Euskadi.

2) Ley Foral 14/1996, de 2 de julio, de Cooperativas de Navarra.

3) Ley 8/2003, de 24 de marzo, de cooperativas de la Comunidad Valenciana.

4) Ley $2 / 1998$, de 26 de marzo, de Sociedades de Cooperativas de Extremadura.

5) Ley 5/1998, de 18 de diciembre, de Cooperativas de Galicia.

6) Ley $6 / 1998$, de 13 de mayo, de regulación del funcionamiento de las Secciones de Crédito de las Cooperativas de Cataluña. Ley 18/2002, de 5 de julio, de Cooperativas de la Comunidad Autónoma de Cataluña.

7) Ley 9/1998, de 22 de diciembre, de Cooperativas de Aragón.

8) Ley 2/1999, de 31 de marzo, de Sociedades Cooperativas Andaluzas. Ley 3/2002, de 16 de diciembre, por la que se modifica la Ley 2/1999, de 31 de marzo, de Sociedades Cooperativas Andaluzas.

9) Ley 4/1999, de 30 de marzo, de Cooperativas de la Comunidad de Madrid.

10) Ley $4 / 2001$, de 2 de julio, de Cooperativas de La Rioja.

11) Ley $2 / 1998$, de 26 de marzo, de Sociedades Cooperativas de Extremadura. Ley 8/2006, de 23 de diciembre de Sociedades Cooperativas Especiales de Extremadura. Ley 5/2001, de 10 de mayo, de Crédito Cooperativo (Extremadura).

12) Ley 4/2002, de 11 de abril, de Cooperativas de la Comunidad de Castilla y León.

13) Ley 20/2002, de 14 de noviembre, de Cooperativas de Castilla-La Mancha.

14) Ley $1 / 2003$, de 20 de marzo, de cooperativas de Baleares.

15) Ley 8/2006, de 16 de noviembre, de Sociedades Cooperativas de la Región de Murcia. 
La sujeción de las cooperativas al estatuto jurídico del empresario conlleva muchas dificultades a la hora de aplicar a aquéllas las instituciones mercantiles. No obstante, no ocurre así con la Ley 22/2003, de 9 de julio, Concursal (LC). Esta norma, a diferencia de lo que ocurría con la anterior legislación española sobre insolvencia (suspensión de pagos y quiebra), se aplica tanto a la persona física, como a la jurídica, siendo indiferente su naturaleza civil o mercantil?.

La Ley Concursal, que se promulgó en tiempos de bonanza económica, se ha venido aplicando en situación de crisis severa, lo que ha provocado constantes reformas, la mayoría de gran calado. En una de estas reformas, la llevada a cabo por el Real Decreto-ley 3/2009, de 27 de marzo, de medidas urgentes en materia tributaria, financiera y concursal, se introdujo la institución de los acuerdos de refinanciación añadiendo una nueva disposición adicional cuarta a la LC.

El acuerdo de refinanciación se presentó como figura muy oportuna en un contexto de crisis financiera en el que las empresas necesitan renegociar su pasivo con las entidades de crédito. La renegociación, hasta entonces, podía conllevar la rescisión concursal si se realizaba en los dos años anteriores a la declaración de concurso y resultaba perjudicial (art. 71 LC). Además, el refinanciador podía ser considerado acreedor de mala fe -conocedor de la situación de insolvencia- y, consiguientemente, sus créditos ser calificados como subordinados (art. 73 LC) ${ }^{8}$. El RD Ley 3/2009 dejará inmunes a la rescisión determinados acuerdos de refinanciación de estos acreedores financieros ${ }^{9}$. Ahora

16) Ley 4/2010, de 29 de junio, de Cooperativas de la Comunidad Autónoma del Principado de Asturias.

17) Ley 6/2013, de 6 de noviembre, de Cooperativas de Cantabria. Vid. GADEA, E. «Ley 6/2013, de Cooperativas de Cantabria: contenido y oportunidad para el desarrollo de la economía social, Deusto Estudios Cooperativos, N. ${ }^{\circ}$, 2014, págs. 155-174.

7 Señala el art. 1 LC (Presupuesto objectivo): «1. La declaración de concurso procederá respecto de cualquier deudor, sea persona natural o jurídica. 2. El concurso de la herencia podrá declararse en tanto no haya sido aceptada pura y simplemente. 3. No podrán ser declaradas en concurso las entidades que integran la organización territorial del Estado, los organismos públicos y demás entes de derecho público».

8 La SJMerc. n. ${ }^{\circ} 1$ de Madrid, de 21 de mayo de 2007 (AC 2008, 1603), por ejemplo, calificó de acreedor subordinado al acreedor bancario refinanciador.

9 Valpuesta, E., señala que a pesar de que la razonabilidad de la refinanciación impedía tachar de arbitraria esta medida y que los demás acreedores se sintieran perjudicados, la nueva norma nació con un cierto estigma de ser fruto de un "chantaje» de las entidades de crédito al poder público y el hecho de que la regla se incorporara mediante un Decreto-Ley y en una situación excepcional de crisis la teñía de un cierto «oportunismo». En opinión de este autor, no se trataba de una pieza del Derecho concursal realizada dentro de la reforma global y ordenada de la Ley concursal de 2003. En 
bien, la fase previa de negociación de un acuerdo de refinanciación no impedía que un acreedor solicitara la declaración de concurso, que se lograba si existía una situación de insolvencia ${ }^{10}$.

El deterioro de la situación económica y la persistencia de la dificultad de financiación de las empresas motivó que la Ley 38/2011, de 10 de octubre, de reforma de la Ley 22/2003, de 9 de julio, Concursal diera nueva redacción a la DA cuarta LC. Esta reforma dará relevancia a la comunicación formal de que se están iniciando negociaciones con los acreedores, regulará los deberes de las partes que negocian el acuerdo ${ }^{11}$ y, sobre todo, establecerá la homologación judicial de tal acuerdo ${ }^{12}$, cuya consecuencia es, dentro de ciertos límites, su extensión a los acreedores disidentes. Además, incorporará a nuestro ordenamiento el llamado "privilegio del dinero nuevo"13».

su opinión se trataba de un remedio ortopédico, incorporado gracias a (o a causa de) la situación de crisis «Los «Acuerdos de refinanciación en el proyecto de reforma de la Ley Concursal», Revista de Derecho Concursal y Paraconcursal, núm. 15, 2011, p. 157. Este autor ya había mantenido esta opinión en el «Comentario a la disposición adicional cuarta», en AA.VV., Comentarios a la Ley Concursal, Thomson-Aranzadi, 2010, vol. II, pág. 1060. También se muestra crítico con las reformas realizadas en función de una situación de crisis concreta Sánchez-Calero, J., «Refinanciación y reintegración concursal, eprints.ucm.es/9658/1/Refinanciaconcursal.pdf, 2009, págs. 12-14. Moya, J., califica la norma de apresurada, «Los acuerdos de refinanciación de la nueva disposición adicional cuarta de la Ley Concursal», Revista Aranzadi Doctrinal, n. ${ }^{\circ}$ 8/2009, pág. 32. Para Pulgar, J., la reforma no tuvo como origen la situación de crisis, sino razones de eficiencia y equidad sostenibles también en épocas de bonanza, «Estrategias preconcursales y refinanciaciones de deuda: escudos protectores en el marco del RDL/2009 Implicaciones financieras de la ley concursal: adaptado al real decreto-ley 3/2009, de 27 de marzo / coord. por Alonso/Pulgar, 2009, págs. 52-53.

10 Sobre la imposibilidad de aplicar con anterioridad a la Ley 38/2011 el art. 5.3 LC a los supuestos de negociación de un acuerdo de refinanciación vid. Fernández Torres, I., «Algunas consideraciones en torno a la refinanciación de deuda y la posibilidad de no presentar declaración de concurso (A propósito del auto del Juzgado de Primera Instancia n. ${ }^{\circ} 9$ y Mercantil de Córdoba de 10 de septiembre de 2009», RCP, n. ${ }^{\circ}$ 12/2010, págs. 257-269.

11 Vid. al respecto García Vicente, J.R., «Deberes en la negociación y responsabilidad precontractual» en Los acuerdos de refinanciación, págs. 67-91.

12 En relación con el procedimiento de homologación previsto en la Ley 38/2011 vid. Cervera, M., «Procedimiento de solicitud de homologación judicial de acuerdo preconcursal de refinanciación (Comentario al auto del juzgado mercantil n. ${ }^{\circ} 6$ de Barcelona de 5 de junio de 2012)», La Ley, n. ${ }^{\circ}$ 17, págs. 195 y Ss., y López Sánchez, J., «El procedimiento de homologación de acuerdos de refinanciación», Los acuerdos de, págs. 293-318. En materia de impugnación, vid. García-Rostán, G., «Impugnación de la homologación del acuerdo de refinanciación», Los acuerdos, págs. 483-494.

13 El privilegio del dinero nuevo o fresh money, consiste en la calificación como crédito prededucible en su mitad, y privilegiado general en la otra mitad, de ciertos créditos concedidos en el ámbito de los acuerdos de refinanciación contemplados en el art. 71.6 LC. 
La reforma de Ley 14/2013, de 27 de septiembre, de apoyo a los emprendedores y su internacionalización, en materia de acuerdos de refinanciación regulará de una manera más completa y más flexible el procedimiento registral de designación de los expertos, e incluirá una regla más flexible y clara del cómputo de la mayoría del pasivo que suscribe el acuerdo y que constituye el requisito legal mínimo para su potestativa homologación judicial. Esta Ley desvinculará las refinanciaciones homologadas judicialmente de las irrescindibles del artículo 71.6 LC. Así, si un acuerdo homologado judicialmente no cumplía los requisitos de dicho articulo, no resultaba irrescindible frente a las acciones concursales - lo que no significaba que fuera en sí mismo perjudicial y rescindible.

Sin tiempo de digerir los cambios introducidos por la Ley de emprendedores, el Real Decreto-Ley 4/2014 acometerá reformas más profundas todavía. El Gobierno justifica la extraordinaria y urgente necesidad que motiva el empleo de esta norma en la capital importancia de garantizar, sin dilación, la eliminación de los obstáculos que impiden, en la práctica, el éxito de operaciones de reestructuración y refinanciación de empresas que ya estén en marcha, o que deban acometerse de manera inmediata. Así, esta norma convierte las refinanciaciones homologadas en irrescindibles y de la DA $4{ }^{a}$ parece desprenderse que la homologación judicial dota al acuerdo de carácter «no perjudicial». De otra parte, extiende los efectos de los acuerdos homologados a los acreedores disidentes y ausentes sin garantía real, lo que supone un cambio considerable y complejo en relación con la anterior normativa. Además, si un 75\% de los acreedores financieros así lo deciden, los bancos disidentes o no participantes pueden verse obligados a aceptar inmuebles en lugar de metálico. El Real Decreto Ley 4/2014 incorpora elementos de resolución extrajudicial de la situación de insolvencia que se han venido aplicando en los últimos años en los países de nuestro entorno. Estos elementos han demostrado su efectividad en la conservación de las empresas en dificultades financieras al aumentar las posibilidades de pago del deudor.

No acaban ahí las reformas de la LC, las últimas se han producido por las Leyes 17/2014, de 30 de septiembre, por la que se adoptan medidas urgentes en materia de refinanciación y reestructuración de deuda empresarial; 9/2015, de 25 de mayo, de medidas urgentes en materia concursal, 25/2015, de 28 de julio, de mecanismo de segunda oportunidad, reducción de la carga financiera y otras medidas de orden social, y 40/2015, de 1 de octubre, de Régimen Jurídico del Sector Público.

Los incesantes cambios, han provocado que la Ley Concursal, en general, y los acuerdos de refinanciación, en particular, hayan perdido 
la uniformidad inicial en su espíritu y en su estructura. Las últimas reformas se han sucedido, sin tiempo de valorar los efectos de las anteriores. Resulta así difícil extraer conclusiones fiables cuando se observa un determinado fenómeno, como es el caso del que analizaremos en este trabajo: las cooperativas han comenzado a acudir a la figura del acuerdo de refinanciación, como vía para superar su crisis, en el momento en que las sociedades capitalistas (anónimas y limitadas), están abandonando su empleo.

En el presente artículo, partiendo del marco normativo de los acuerdos de refinanciación y de sus efectos y del comportamiento de las cooperativas ante la crisis, se pretende hacer una valoración de los motivos que han podido llevar a las cooperativas a acudir a esta institución para superar su crisis. Para ello, se tendrá en cuenta el contenido de las negociaciones que se han realizado y homologado judicialmente.

\section{Cooperativas y crisis}

La doctrina ha señalado que la diferente finalidad social con la que se constituyen las cooperativas (voluntad cooperativa - que repercute en el compromiso con la sociedad-) y las sociedades de capital (ánimo de lucro) tiene reflejo a la hora de afrontar una crisis ${ }^{14}$. Así, las cooperativas pueden mantenerse aun sin beneficios, mientras no se llegue a los límites económicos de su disolución, porque sus socios prefieren resistir. Con este propósito pueden acordar dotaciones económicas de sostenimiento, como el incremento o establecimiento de cuotas extraordinarias, o el aval por los propios socios de crédito mercantil para la sociedad, con la idea de que más vale obligarse que perder el empleo. Por el contrario, en las sociedades de capital las crisis provocan de inmediato desinversiones y pérdida de empleo, por-

14 Como señala Martínez Charterina, A., al ser las cooperativas empresas, reciben el impacto de la crisis económica, y ese impacto se extiende por la globalización, como sucede con cualquier otra empresa "Las cooperativas frente a la crisis». Boletín de la Asociación Internacional de Derecho Cooperativo Núm. 44/2010, pág. 211, quien realiza un recorrido por las grandes crisis económicas habidas, señalando, entre otras cosas que la última crisis que hemos padecido parece haber cogido por sorpresa a casi todo el mundo, y que las cooperativas son empresas a las que las crisis no resultan extrañas. Muchas veces han nacido en contextos de crisis, y se han enfrentado a ellas, a veces para sucumbir, y las más de las veces para salir fortalecidas a través de las oportunidades que también les ofrecen. De acuerdo con el autor, una empresa con futuro tiene que ser capaz de innovar de forma constante, tiene que llevar a cabo una gestión basada en valores éticos y debe comportarse en el marco de la responsabilidad social empresarial, el modelo cooperativo ofrece claras ventajas porque tales consideraciones conectan con su propia naturaleza. 
que la finalidad se pierde cuando la cuenta de resultados no arroja saldos positivos ${ }^{15}$.

En el contexto cooperativo es característico que, ante una crisis, los socios trabajadores y de trabajo realicen voluntariamente sacrificios laborales (p.ej. se aumenta la jornada laboral sin retribución, se prescinde de festivos y/ o de vacaciones) que pueden consistir en la pérdida directa de ingresos (pérdida de pagas extraordinarias, recorte de los ingresos periódicos ordinarios, anulación de actualizaciones del capital y destino a reservas de todo el resultado económico excedente, entre otras medidas extraordinarias). Y si bien estas medidas no son diferentes de las que adoptan las sociedades de capital para contener el gasto, su eficacia es mayor en las cooperativas ${ }^{16}$. Ello se justifica en los hechos de contar con mayor información que los socios de las sociedades de capital, de considerar la sociedad suya, y de hacerse, consecuentemente, responsables de la superación de la crisis que afecta a todo el colectivo ${ }^{17}$. Y todas estas decisiones son asamblearias que, a diferencia del resto de sociedades, implica que los cooperativistas restringen sus beneficios, sin que de ello derive conflictividad por cuanto que el voto de la mayoría lo impide ${ }^{18}$.

15 Divar, J. I, «Las cooperativas ante la crisis económica» Boletín de la Asociación Internacional de Derecho Cooperativo Núm. 44/2010, pág. 269-270. Vid., también «Las cooperativas: una alternativa económica y social frente a la crisis Boletín de la Asociación Internacional de Derecho Cooperativo, N. 47, 2013, págs. 257-264, En la misma línea, Martínez Chaterina, A., o.c, p. 211 y ss. que, en relación con las cooperativas de trabajo, cita a Javier Divar quien formula las razones que, con carácter general, invitan al fomento público de las cooperativas de trabajo en épocas de crisis económica Divar, J.I.: «Crisis económica, cooperativismo e innovación», en Boletín de la Asociación Internacional de Derecho Cooperativo, ${ }^{\circ}$ 43, Universidad de Deusto, Bilbao, 2009, págs. 200 y ss. y a Goio Hernando hace referencia recoge las medidas concretas adoptadas en las cooperativas de Mondragón (MCC) Hernando, G, «La crisis económica y su impacto en el marco de las relaciones laborales: la respuesta de las cooperativas como tercera vía», en Boletín de Estudios Económicos, n. ${ }^{\circ} 196$, Universidad Comercial de Deusto, Bilbao, 2009, págs.188 y ss.

16 Hernando, G. quien refiere que fuera del modelo cooperativo se pueden encontrar empresas en crisis que reducen sus plantillas y a la vez reparten beneficios entre sus accionistas, o plantean un ERE con incrementos salariales por encima del $1 \%$ (referente de la patronal para la negociación colectiva de 2009). Partiendo del hecho de que las cooperativas de Mondragón constituyen una corporación, este autor recoge las medidas corporativas previstas para ayudar a las cooperativas declaradas en desempleo estructural (con un excedente de plantilla que afecte significativamente a su situación, que no puedan absorber por sí mismas, y que tenga una cuenta de resultados con pérdidas). Estas ayudas incluyen prestaciones por desempleo, indemnizaciones, prejubilaciones, reconversión profesional, y reubicaciones o.c., págs. 190 y ss.

17 Martínez Charterina, A., o.c. p. 216, quien señala que la autoayuda, self-help, se entiende no sólo como ayuda a uno mismo sino también como ayuda de unos a otros, y que la autoayuda se prolonga en la solidaridad.

18 Divar, J. I, «Las cooperativas, o.c., pág. 270-271. 
La mayor resistencia de las cooperativas a la crisis también ha sido puesta de manifiesto por la propia Alianza Cooperativa Internacional ${ }^{19}$ sobre la base del informe «Resilience of the cooperative business model in time of crisis» 20 elaborado en el año 2009 para la Organización Internacional del Trabajo $(\mathrm{OIT})^{21}$. En este informe, se hace referencia expresa a las cooperativas financieras, a las agrarias, a las de consumo y a las de trabajo de trabajo asociado. En relación con las primeras, esto es, bancos cooperativos y uniones de crédito, el informe señala aumentos de sus activos y depósitos, del volumen de los préstamos, y del número de socios, mejores tipos de interés en relación con los de los competidores, mayor estabilidad medida a través de coeficientes de suficiencia de capital y de tasa de impagados, pocas pérdidas de inversiones y poca necesidad de ayuda pública22.

Dicho lo anterior, veamos las siguientes tablas:

a) Número de sociedades anónimas, de responsabilidad limitada y cooperativas que iniciaron procesos de insolvencia entre los años 1997 y 2004 (en este período no se aplicaba la Ley 22/2003, de 9 de julio, Concursal (LC).

Tabla comparativa de la evolución de la crisis en sociedades anónimas, limitadas y cooperativas ${ }^{23}$

\begin{tabular}{|c|c|c|c|c|c|c|c|c|c|c|c|c|c|c|c|c|}
\hline & \multicolumn{2}{|c|}{1997} & \multicolumn{2}{|c|}{1998} & \multicolumn{2}{|c|}{1999} & \multicolumn{2}{|c|}{2000} & \multicolumn{2}{|c|}{2001} & \multicolumn{2}{|c|}{2002} & \multicolumn{2}{|c|}{2003} & \multicolumn{2}{|c|}{2004} \\
\hline & 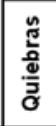 & 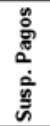 & 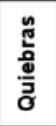 & 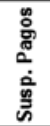 & 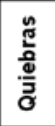 & 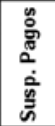 & 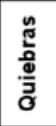 & 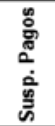 & 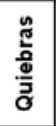 & 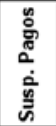 & 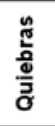 & 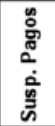 & 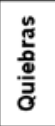 & 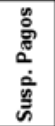 & 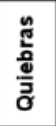 & 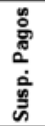 \\
\hline Sociedad Anónima & 319 & 309 & 222 & 217 & 205 & 122 & 173 & 129 & 136 & 92 & 172 & 119 & 138 & 112 & 151 & 107 \\
\hline ociedad Limitad & 263 & 163 & 290 & 147 & 273 & 112 & 283 & 105 & 306 & 109 & 416 & 128 & 397 & 143 & 492 & 118 \\
\hline & 8 & 6 & 4 & - & 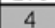 & $=$ & 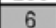 & - & & - & 10 & 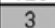 & 7 & - & 0 & \\
\hline
\end{tabular}

19 Mensaje del 87. ${ }^{\circ}$ Día Internacional de las Cooperativas de la $\mathrm{ACl}, 15 .^{\circ}$ Día Internacional de las Cooperativas de Naciones Unidas, celebrado el 4 de julio de 2009, titulado «Impulsando la recuperación global a través de las Cooperativas».

20 Informe elaborado por Johnston Birchall y Lou Hammond Ketilson.

21 Puede consultarse este informe en:

http://www.ilo.org/empent/Publications/WCMS_108416/lang--en/index.htm.

22 Así lo recoge Martínez Charterina, A, "Las cooperativas», o.c. p. 211, refiriéndose también, en relación con las cooperativas de consumidores, a Rodrigo Gouveia que relata el esfuerzo de las cooperativas de Finlandia, Reino Unido e Italia para conseguir el éxito en época de crisis. Gouveia, R.: «Combatir la crisis económica global con la cooperación del consumidor», en Cuadernos de Economía Social, n. ${ }^{\circ} 3$, CEPES, Madrid, 2009, págs. 6-7.

23 https://cdn.informa.es/sites/5809ccf0cdaeee62837a6c07/content_entry5809cd5ecdaee e62837a6c51/591e8f8111911f00b0ef659f/files/HistoricoConcursos_2017.pdf?1495175041 
b) Número de sociedades anónimas, de responsabilidad limitada y cooperativas que iniciaron procesos de insolvencia entre los años 2005 y 2016, (período con la aplicación de la LC):

Tabla comparativa de la evolución de la crisis en sociedades anónimas, limitadas y cooperativas ${ }^{24}$

\begin{tabular}{|l|c|c|c|c|c|c|c|c|c|c|c|c|}
\hline & 2005 & 2006 & 2007 & 2008 & 2009 & 2010 & 2011 & 2012 & 2013 & 2014 & 2015 & 2016 \\
\cline { 2 - 24 } & Concursos & Concursos & Concursos & Concursos & Concursos & Concursos & Concursos & Concursos & Concursos & Concursos & Concursos & Concursos \\
\hline Sociedad Anónima & 318 & 214 & 230 & 523 & 978 & 936 & 997 & 1.372 & 1.585 & 1.078 & 701 & 478 \\
\hline Sociedad Limitada & 750 & 639 & 687 & 2.041 & 3.747 & 4.002 & 4.510 & 6.008 & 7.086 & 5.356 & 4.124 & 3.435 \\
\hline Cooperativa & 15 & 11 & 15 & 20 & 39 & 56 & 99 & 98 & 129 & 100 & 84 & 65 \\
\hline
\end{tabular}

c) Comparativa del número de constituciones sociedades anónimas, limitadas y cooperativas, desde el año 2005 al 2016.

Tabla comparativa de la evolución de constituciones de S.A, SRL, y Cooperativas ${ }^{25}$

\begin{tabular}{|c|c|c|c|c|c|c|c|c|c|c|c|c|}
\hline & 2005 & 2006 & 2007 & 2008 & 2009 & 2010 & 2011 & 2012 & 2013 & 2014 & 2015 & 2016 \\
\hline & 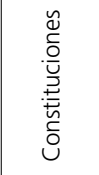 & 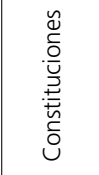 & 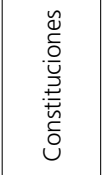 & 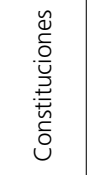 & 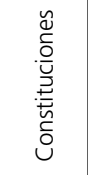 & 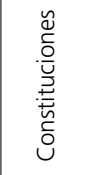 & 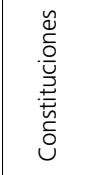 & 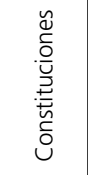 & 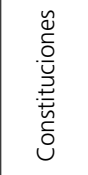 & 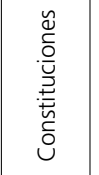 & 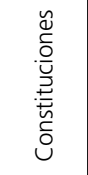 & 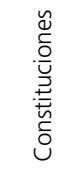 \\
\hline S.A & 2.141 & 2.029 & 1.904 & 1.283 & 753 & 737 & 653 & 555 & 550 & 687 & 622 & 407 \\
\hline S.R.L & 131.054 & 141.830 & 138.879 & 99.473 & 74.333 & 75.885 & 81.027 & 84.399 & 90.373 & 91.544 & 91.750 & 98.824 \\
\hline Coop & 1.609 & 1.304 & 1.140 & 1.032 & 1.021 & 1.088 & 974 & 1.005 & 1.166 & 1.293 & 1.350 & 1.400 \\
\hline
\end{tabular}

Como se observa, la resistencia de las cooperativas a la crisis, en comparación con las sociedades de capital anónima y limitada, resulta evidente hasta el año 2008. A partir de esa fecha, la resistencia comienza a debilitarse progresivamente, llegando a su momento más dramático en el año 2013 para, posteriormente, comenzar a recuperarse. La crisis afecta, no sólo al número de procedimientos concursales

24 https://cdn.informa.es/sites/5809ccf0cdaeee62837a6c07/content_entry5809cd5ecdaee e62837a6c51/591e8f8111911f00b0ef659f/files/HistoricoConcursos_2017.pdf?1495175041.

25 Información extraída de: http://www.rmc.es/estadisticas/EstadisticaSocietaria.aspx

http://www.empleo.gob.es/es/sec_trabajo/autonomos/economia-soc/EconomiaSocial/ estadisticas/ 
iniciados, sino, también, al número de sociedades constituidas en las mismas fechas. Es, asimismo, destacable el descenso en la elección de la sociedad anónima como forma social de inicio de actividad, en favor de la sociedad de responsabilidad limitada.

La crisis financiera afecta, fundamentalmente, a las Pymes y a las microempresas, dado que, a medida que aumenta el tamaño de la empresa ${ }^{26}$, se reduce la necesidad y dependencia de la financiación bancaria y viceversa ${ }^{27}$. Esta circunstancia se considera un factor de la crisis que se ha venido padeciendo, a lo que debe sumarse el hecho de que, a medida que se incrementa la financiación bancaria, más se reduce la inversión en I+D de las empresas industriales y viceversa ${ }^{28}$.

\section{Cooperativas y homologación de los acuerdos de refinanciación}

\section{III.1. El papel de las entidades financieras en las refinanciaciones}

La influencia del mercado financiero en la economía real es incuestionable. Las entidades financieras y los mercados de capitales tienen un papel protagonista en cualquier economía desarrollada, financiando a las empresas y a las familias, gestionando y garantizando la integridad de los ahorros, y facilitando los pagos y transferencias de fondos entre los operadores económicos. Por ello, el crecimiento económico y, con ello, prosperidad para las personas, requiere de un sistema finan-

26 A efectos tributarios, Gran Empresa se considera la sociedad con un volumen de operaciones en el ejercicio anterior superior a 6.010.121,04 euros.

http://www.agenciatributaria.es.

27 Sánchez Ruiz de Valdivia, I. «Crisis económica y Mercado Único Hipotecario: transparencia, ineficacia y segunda oportunidad para consumidores/as y empresarios/as (autónomos, microempresas y Pymes)», pág. 44. Esta autora propone soluciones para el drama social que viven las personas físicas, empresarios y no empresarias, y jurídicas (microempresas y Pymes), que pongan fin al sobreendeudamiento familiar, analizando para ello la Directiva 2014/17/UE del Parlamento y del Consejo sobre los contratos de crédito celebrados con consumidores para bienes inmuebles de uso residencial, que tiene por objeto crear un Mercado Único Europeo eficiente, competitivo, transparente y eficaz que apueste por la concesión de créditos hipotecarios responsables y eleve la protección de quien contrata, y las reformas del régimen de segunda oportunidad introducidas por la Ley 25/2015, de 28 de julio, de mecanismo de segunda oportunidad, reducción de la carga financiera y otras medidas de orden social en el régimen legal previsto en el RDL 1/2015, de 27 de febrero. Presente y Futuro págs. 41-86.

28 Maroto, J.A. "Rasgos (preocupantes) de la financiación bancaria a las empresas industriales». Registradores, n. ${ }^{\circ}$ 72, abril-junio, 2015, pág. 45. 
ciero estable y que funcione bien. El negocio bancario requiere confianza. Esta confianza la otorgan determinadas instituciones, como el Fondo de Garantía de Depósitos, el Banco de España en cuanto prestamista de última instancia y miembro del Eurosistema, y el mantenimiento de la cultura de pago 29 .

En el concurso de acreedores, la situación privilegiada de las entidades de crédito, agrava, cuando hay crisis, el efecto de encadenamiento de concursos. Si los empresarios no pueden cobrar sus créditos, tampoco pueden pagar sus deudas (con especial incidencia en los autónomos, microempresas y Pymes, que representan el $99 \%$ del tejido empresarial español). De ahí que las reformas en la LC, se hayan dirigido a reducir la situación privilegiada de los créditos que, por regla general, ostentan las entidades bancarias hayan tenido como objetivo paliar ese efecto. Ocurre, no obstante, que ello puede repercutir negativamente en el mercado financiero (en especial, en el hipotecario), de modo que resulte, todavía más difícil, el acceso a la financiación y refinanciación para los pequeños y medianos empresarios (los más necesitados de crédito para iniciar o continuar su actividad).

\section{III.2. Efectos y extensión de la homologación.}

La homologación judicial de los acuerdos de renegociación del pasivo entre una empresa y las entidades de crédito para superar una crisis, tiene, conforme al artículo 1.809 del Código civil, el efecto de una transacción de carácter judicial. Por consiguiente, produce efectos de cosa juzgada respecto del mismo, respetándose así la naturaleza contractual de este tipo de acuerdos entre quienes los han suscrito ${ }^{30}$.

No abordaremos aquí el régimen jurídico de la homologación, que se contiene en la extensa disposición adicional cuarta de la Ley Concursal ${ }^{31}$,

29 Linde de Castro, I. «Prólogo», Presente y Futuro del Mercado Hipotecario y Ley de Segunda Oportunidad para Consumidores/as y Empresarios/as, (Dir. Sánchez Ruiz de Valdivia, I, y Olmedo, M.), Edit. Aranzadi 2015.

30 Así se recoge en las resoluciones judiciales de homologación.

31 Señala el n. 1 en su párrafo primero de la Disposición adicional cuarta LC (Homologación de los acuerdos de refinanciación): «Podrá homologarse judicialmente el acuerdo de refinanciación que habiendo sido suscrito por acreedores que representen al menos el 51 por ciento de los pasivos financieros, reúna en el momento de su adopción, las condiciones previstas en la letra a) y en los números $2 .^{\circ}$ y $3 .^{\circ}$ de la letra b) del apartado 1 del artículo 71 bis. Los acuerdos adoptados por la mayoría descrita no podrán ser objeto de rescisión. La letra a) y los números $2 .^{\circ}$ y $3 .^{\circ}$ de la letra b) del apartado 1 del artículo 71 bis señalan: 
y ha sido prolíficamente tratado por la doctrina ${ }^{32}$. Señalaremos aquí cuatro puntos relevantes a los efectos de este artículo:

a) La homologación supone la extensión de un acuerdo de refinanciación a los «acreedores de pasivos financieros». En la introducción inicial de la figura por la Ley 38/2011, la homologación afectaba únicamente a «entidades financieras», con lo cual resultaba claro quiénes eran los destinatarios de la norma. La extensión actual a todo pasivo financiero (con la imprecisión, además, que introduce este término) disminuye la relevancia de las entidades de crédito, pero siguen siendo los principales acreedores afectados por la homologación (junto con los obligacionistas).

«1. No serán rescindibles los acuerdos de refinanciación alcanzados por el deudor, así como los negocios, actos y pagos, cualquiera que sea la naturaleza y la forma en que se hubieren realizado, y las garantías constituidas en ejecución de los mismos, cuando:

a) En virtud de éstos se proceda, al menos, a la ampliación significativa del crédito disponible o a la modificación o extinción de sus obligaciones, bien mediante prórroga de su plazo de vencimiento o el establecimiento de otras contraídas en sustitución de aquéllas, siempre que respondan a un plan de viabilidad que permita la continuidad de la actividad profesional o empresarial en el corto y medio plazo; y

b) Con anterioridad a la declaración del concurso:

2. ${ }^{\circ}$ Se emita certificación del auditor de cuentas del deudor sobre la suficiencia del pasivo que se exige para adoptar el acuerdo. De no existir, será auditor el nombrado al efecto por el registrador mercantil del domicilio del deudor y, si éste fuera un grupo o subgrupo de sociedades, el de la sociedad dominante.

3. ${ }^{\circ}$ El acuerdo haya sido formalizado en instrumento público al que se habrán unido todos los documentos que justifiquen su contenido y el cumplimiento de los requisitos anteriores.»

32 Aparte de la obra de Pulgar, J., puede verse para la regulación inicial Azofra, F., "La invulnerabilidad de los acreedores financieros con garantía real a la homologación judicial de los acuerdos de refinanciación», RDCP, núm. 16, 2012, págs. 127-141; Senés, M. C., "La homologación de los acuerdos de refinanciación», ADCo, núm. 30, 2013, págs. 47-74; García-Cruces, J.A. (dr.), Los acuerdos de refinanciación y de reestructuración de la empresa en crisis: autonomía de la voluntad e insolvencia empresarial, 2013. En cuanto a la regulación existente tras las últimas reformas, véanse: Cerdá, F., «La extensión de efectos del acuerdo de refinanciación, homologado judicialmente, a los acreedores financieros disidentes o no partícipes», $A D C 0$, núm. 33, 2014, págs. 143165; Cervera, M., «El procedimiento de homologación de acuerdos de refinanciación», ADCo, núm. 33, 2014, págs. 111-123; Quijano, J., «La homologación judicial de los acuerdos de refinanciación», Estudios jurídicos en memoria del profesor Emilio Beltrán, tirant lo Blanch, Valencia, 2015, págs. 1512-1538; Fernández Rodríguez, A., «El nuevo concepto del "sacrificio desproporcionado" y sus implicaciones», RDCP, núm. 22, 2015, págs. 241-249; Sancho, I., "Homologación, eficacia, impugnación y rescisión de los acuerdos de refinanciación», en Díaz Moreno - León Sanz (drs.), Acuerdos de Refinanciación, Convenio y Reestructuración, Aranzadi, Cizur Menor (Navarra), 2015, págs.. 145-181; Vaquer, F. J. «La homologación judicial de acuerdos de refinanciación tras la Ley 17/2014, de 30 de septiembre», RDCP, N. 22, 2015, págs. 223-240. 
b) Si bien en un primer momento la homologación no afectaba a los créditos dotados de garantía real, en la redacción actual sí se extiende a los acreedores con garantía real por la parte que no quede cubierta con el valor del bien afecto a la garantía (disp. adic. cuarta, apartado 3, inciso primero LC). Pero, además, incluso por la parte cubierta por la garantía se puede ahora extender los acuerdos de refinanciación a los créditos con garantía real si una mayoría del pasivo financiero garantizado ha votado a favor de los acuerdos (DA cuarta, apartado cuarto LC). De este modo, incluso un acreedor hipotecario con un bien afecto de valor muy superior al crédito, puede verse afectado por acuerdos que le perjudican notablemente.

c) En la regulación inicial, únicamente se extendían las «esperas» a los mencionados acreedores. Sin embargo, actualmente, cabe extender no sólo «esperas», sino también «quitas» y conversión de deudas en préstamos participativos o en acciones o participaciones de la sociedad deudora, siempre que se cumplan una serie de requisitos. Entre ellos, unas mayorías, que son tanto más altas cuanto más gravosa es la consecuencia que se extiende (p.ej., se necesita que vote a favor del acuerdo un $80 \%$ del pasivo garantizado, para que pueda extenderse al resto una espera de cinco o más años, y en ningún caso superior a diez, o una quita, DA cuarta, apartado 4.b)). Así, un acreedor bancario que no tenga mucha relevancia cuantitativa dentro del pasivo del deudor, puede verse "arrastrado» por una espera, y también por una quita, a pesar de que su crédito se halle garantizado con hipoteca.

d) La única «defensa» del acreedor financiero disidente ante esta homologación será impugnarla por dos motivos: la concurrencia de los porcentajes exigidos, y la valoración del «carácter desproporcionado del sacrificio exigido» (la doctrina reconoce que para alegar otras cuestiones podría acudir a un juicio declarativo ordinario, que no estaría regulado en la Ley concursal). Este "carácter desproporcionado» implica que el acuerdo de refinanciación, y el sacrificio exigido a los acreedores a los que se extiende, debe estar justificado por la situación financiera de la empresa, y también por el plan de viabilidad que se acompaña al acuerdo de refinanciación. Pero se trata de una expresión muy imprecisa, y puede resultar muy complicado en la práctica determinar si el sacrificio es o no proporcionado. Esto supone que la situación del 
acreedor financiero disidente no sea «fuerte» si pretende ejercitar con éxito esta impugnación.

El marco regulatorio de los acuerdos de refinanciación, permite pensar, tras las últimas reformas de la LC, que si los acreedores financieros no cuentan con créditos útiles: la hipoteca no es intocable —ni aun cuando el bien garantizado sea de mucho valor-, y pueden verse afectados por convenios que les impongan esperas y quitas, van a restringir el préstamo de dinero. Esto reduciría, todavía más, la financiación de las empresas, máxime en una economía tan «bancario-dependiente» como la española, en la que la financiación mediante títulos alcanza menos del $20 \%$ de la total; o lo prestará, pero exigiendo garantías más resistentes al concurso (p.ej. garantías personales, o garantías reales sobre bienes que no sean titularidad del deudor $)^{33}$.

Si bien es cierto que los acuerdos de refinanciación nunca han tenido mucho predicamento en la práctica concursal, lo cierto es que, en el caso de las sociedades capitalistas, se está consolidando una tendencia a la baja que podría confirmar la disminución en la concesión de crédito por las entidades bancarias. Así, en el año 2014, se homologaron 31 acuerdos, en 2015 se homologaron 94 acuerdos (2\% del total de concursos), y, en 2016 se homologaron 90 acuerdos (2\% del total de concursos) ${ }^{34}$. En este año, 2016, en los primeros meses se incrementaron en un $20 \%$ los acuerdos homologados (en mayo aumentó un $28 \%$ ), però, a partir de junio comenzó un descenso que se materializó en septiembre con un decrecimiento del 3\%, en octubre, estancándose entonces. En 2015/2016 la disminución total es de un 4\% En el mes de enero de 2017 el número de acuerdos ha sido tan solo de 5, frente a los 12 que hubo en el mismo periodo en 2016 y en 2015. Esta disminución representa un descenso del $58 \%$ en relación con años anteriores $^{36}$.

33 Vid. Torrubia, B. «El empeoramiento de la «situación privilegiada» de los créditos bancarios en el concurso». RDBB, N. ${ }^{\circ}$ 145, 2017, págs. 155-171.

34 El estancamiento es consecuencia de la disminución del número de concursos, que hace que el ratio aumente, porque los acuerdos de refinanciación homologados ha disminuido.

35 https://www.economistas.es/Contenido/REFor/Datorefor/ANaLISIS\%20ACUERDOS\%20DE\%2OREFINANCIACION\%2OHOMOLOGADO\%20ENERO\%202017\%20\%20 Y\%20COMPARATIVA\%202015\%20Y\%202014.pdf

36 https://www.economistas.es/Contenido/REFor/Datorefor/ANaLISIS\%20ACUERDOS\%2ODE\%2OREFINANCIACION\%2OHOMOLOGADO\%20ENERO\%202017\%20\%20 Y\%20COMPARATIVA\%202015\%20Y\%202014.pdf 
Sin embargo, en el caso de las cooperativas, y sobre la base de los escasos acuerdos que se han homologado (se han localizado 3 acuerdos en la base de datos (ENDOJ), el efecto ha sido inverso. Así, en el año 2016, se tiene constancia de las dos primeras homologaciones de acuerdos realizados por cooperativas ${ }^{37}$ y en el año 2017 se ha homologado un acuerdo de refinanciación hasta la fecha. En el siguiente punto abordaremos el contenido de dichos acuerdos para intentar extraer alguna conclusión de porqué ha podido ocurrir este llamativo fenómeno.

\section{III.3. Acuerdos de refinanciación celebrados por cooperativas}

\subsection{Auto de FECHA 31/03/2017, DE HOMOLOGACIÓN DE ACUERDO DE

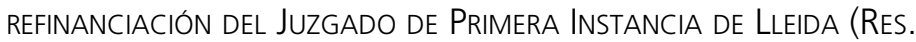 36/2017)}

Este auto homologa un acuerdo que cuenta con el respaldo del $100 \%$ del pasivo financiero alcanzado entre Agropecuaria de Soses SCCL con las entidades bancarias Banco Popular, Ibercaja SA, Caixabank SA, Bankia SA, BBVA SA, Banco de Santander SA, Bankinter SA y Banco Pichincha SA, El acuerdo se firma el 17 de enero de 2017, se califica como novación modificativa ${ }^{38}$, y establece como fecha de vencimiento final de la reestructuración el 18 de enero de 2027. La deuda se fija en un importe agregado aproximado de 7.361.367,54 euros, sin que se acuerden quitas. El contenido del acuerdo, que se recoge en el Auto, puede resumirse así:

37 El 13/02/2015 se homologaron por el Juzgado de lo Mercantil de Bilbao (Res. 75/2015) los acuerdos de refinanciación suscritos por el Grupo Eroski, que integra a Eroski SCoop, con numerosas entidades financieras.

38 El propio Acuerdo establece: "A los efectos oportunos, se deja expresa constancia de que el presente Contrato tendrá la consideración de novación modificativa no extintiva del Acuerdo Marco. Por tanto, serán de aplicación los términos y condiciones del referido Acuerdo Marco que no se vean modificados o alterados con carácter particular y específico en virtud de la presente. Para mayor claridad, el presente Contrato amplía y nova el Acuerdo Marco única y exclusivamente respecto de las materias que aquí se tratan, y, conjuntamente con el Acuerdo Marco, los Instrumentos Financieros y los demás Documentos de la Reestructuración constituyen la totalidad de los acuerdos suscritos entre las Partes en relación con su objeto, quedando expresamente acordado por las mismas que ninguna nueva variación en el contenido del presente Contrato o en el Acuerdo Marco tendrá validez salvo que sea realizada por escrito y firmada por todas y cada una de las Partes, a través de sus respectivos representantes legales autorizados para ello». 
a) Créditos anteriores: Se modifica el período de amortización de los Instrumentos Financieros del Tramo A y del Tramo B (créditos existentes contra la cooperativa), estableciendo un nuevo período de amortización de diez años y un día a contar desde la Fecha de Firma. La amortización se satisfará mediante cuotas trimestrales, con un año de carencia de principal, y con una cuota bullet ${ }^{39}$ pagadera al día siguiente de la última cuota trimestral.

b) Tipo de interés: Se sustituye el aplicable correspondiente a los Instrumentos Financieros de los Tramos A, B (Créditos anteriores) y $D$ (Fresh Money) por uno equivalente al resultado de sumar al Tipo de Interés Ordinario, o en su caso, al Tipo de Interés Sustitutivo, un margen del 2,75\% anual. En caso de que el EURIBOR fuera inferior a cero, el EURIBOR aplicable será cero.

C) Instrumentos Financieros del Tramo D: Nuevo otorgamiento de instrumentos de préstamo, por importe agregado de 940.000 euros. El destino es el siguiente: a) 800.000 euros para necesidades operativas de la Financiada, y b) un máximo de 140.000 euros para cubrir los costes de la Reestructuración (honorarios, gastos, aranceles y suplidos de fedatarios públicos, registros públicos, asesores legales de las Entidades Financieras que intervengan en la formalización e inscripción, en su caso, de los Documentos de la Reestructuración). La amortización del principal y el pago de los intereses se realizará en un período de cinco años a contar desde la Fecha de Firma con las correspondientes cuotas anuales. La fecha de vencimiento final de los Instrumentos Financieros del Tramo D será el 17 de enero de 2022.

En el supuesto de que la Financiada no cumpliera con las obligaciones de pago relativas al tramo D, los Aportantes Subsidiarios de Fondos se comprometen, de forma subsidiaria respecto de la Financiada y a primer requerimiento, a aportar los fondos necesarios para que ésta pueda satisfacer las cuotas anuales relativas al Tramo $\mathrm{D}$ en los siete (7) días naturales siguientes a la fecha de pago de la Financiada y serán realizadas mancomunadamente a prorrata de su respectiva aportación de fruta en la campaña inmediatamente anterior a la

39 El acuerdo deja expresa constancia de que la cuota bullet será equivalente a la suma de cuotas correspondientes a un periodo de cinco (5) años, tomándose en consideración que se ha dividido el total de la Deuda que corresponde al Tramo A y al Tramo B en quince (15) años para realizar los cálculos relativos a la amortización de las mismas en cuotas ordinarias y a la cuota bullet. 
amortización de los Instrumentos del Tramo D. Éstos suscriben el presente Contrato a los solos efectos de asumir estas obligaciones.

d) Se deja expresa constancia de que los Socios no deberán realizar la aportación de 1.200.000 euros que iba destinada a amortización anticipada obligatoria del Tramo B conforme a la cláusula 10.2(e) del Acuerdo Marco.

e) Supuestos de amortización anticipada parcial obligatòria que se añaden:

1. Exceso del precio de venta de la fruta.

2. Exceso del importe de la liquidación al Socio. En relación con los ingresos obtenidos por la Financiada como resultado de la comercialización de la fruta aportada por los Socios o por cualquier otro concepto relacionado con la misma, ésta estará obligada a destinar a amortización anual de forma anticipada aquel importe que debería ser liquidado al Socio como consecuencia de dicha comercialización o por cualquier otro concepto relacionado con la misma y que exceda de 60 céntimos por kilo de fruta (el «Importe Excedente»).

3. Importe no dispuesto relativo a los 140.000 euros del Tramo $\mathrm{D}$ destinados a gastos de la Reestructuración que haya quedado pendiente de disponer.

f) Liberación de la garantía preexistente: La otorgada por la Financiada a favor de Ibercaja relativa a la retención en cuenta de un importe de 500.000 euros en la cuenta corriente $X$ titularidad de la Financiada abierta en dicha entidad.

\subsection{Auto de FeCha 16/06/2016, DE hOMOlOgaCión DE ACUeRDO DE REFINANCIACIÓN DEL JUZGADO DE LO MERCANTIL DE VIGO DE (Res. 84/2016) EXTENSIÓN A ACREEDORES DISIDENTES}

Este Auto, sin recoger el texto del acuerdo de refinanciación, señala que el mismo se ha celebrado entre De Monte Alba SCGallega y 163 acreedores financieros, que representan el 79,655\% de la masa del pasivo total. Dicho acuerdo consiste en la novación modificativa del crédito que ostenta cada acreedor con una quita de un $90 \%$ sobre la cantidad concreta aportada, un período de carencia de dos años, en los que se procederá a la venta de elementos no vinculados propiedad de la sociedad cooperativa, y una espera de diez años. 
3.3. Auto DE FECHA 11/04/2016, DE HOMOLOGACIÓN DE ACUERDO DE REFINANCIACIÓN, DEL JuzGADO de lo MERCANTIL DE TARRAGONA (REs. 90/2016) ACLARADO POR Auto 14/04/2016

En esta resolución, el juez recoge las características del acuerdo de refinanciación celebrado entre Cooperativa Agrícola de Cambrils, S.C.C.L. y sus acreedores financieros a quienes debe 32.632.476,09 de euros:

a) Préstamo hipotecario por parte de la «ASC, S.C.C.L.» (Cooperativa de Crédito), por importe de 10.000.000 de euros, avalado por la Generalitat de Catalunya en 7.500.000. Este préstamo devengará un interés del $2 \%$ en el ejercicio 2016 y de Euribor a un año más un diferencial del $2 \%$ a partir del 1 de enero de 2017. El aval de la Generalitat de Catalunya tendrá un coste anual del $0,8 \%$ del saldo vivo de la cantidad avalada. El préstamo se devolverá mediante cuotas mensuales en un plazo de 20 años, de los cuales los dos primeros con carencia de devolución de capital y los dieciocho restantes mediante cuotas con devolución de capital e intereses.

b) Préstamo participativo concedido por parte de la sociedad pública de la Generalitat de Catalunya, Empresa de Promoció i Localització Industrial de Catalunya, S.A. (AVANÇSA), por un importe de 3.000.000,00.-euros, El tipo de interés considerado es del $5 \%$ (provisional) y la devolución prevista es, en una sola vez, en el año 2023.

c) Aportaciones obligatorias al capital social de la Cooperativa por sus socios productores, por un importe total de 1.500 .000 euros, que debían desembolsarse, como mínimo, en cuanto a 750.000 con anterioridad a la homologación judicial del acuerdo y, el resto, como máximo, el día 30 de septiembre de 2017.

d) Aportaciones voluntarias al capital social de la Cooperativa por parte de los miembros actuales y de los tres últimos años del Consejo Rector y del anterior Director General por un importe de 800.000 euros con anterioridad a la homologación.

e) Respecto a los pasivos financieros cuyo importe asciende a 32.632.476,09 euros, se prevé su pago de acuerdo con el siguiente calendario de pagos:

1. El 40\% (13.052.990,44 euros) en el momento en que se obtenga el líquido de 10.000.000 de euros del préstamo hipotecario de ASC, S.C.C.L.; así como el líquido de 3.000.000 
de euros procedente del préstamo de la sociedad pública de la Generalitat de Catalunya, AVANÇSA

2. Un $32 \%$ (10.442.392,34 euros) de forma aplazada mediante diez pagos anuales, desde abril de 2017 a abril de 2026. Este aplazamiento devengará un interés anual del 0,5\%, pagadero desde abril del año 2017.

3. El restante $28 \%(9.137 .093,31$ euros) se destinará a realizar aportaciones voluntarias no a capital social, que serán retornadas mediante el pago de seis cuotas lineales, la primera en abril de 2027 y la sexta en abril de 2032 y devengarán un tipo de interés anual del 1,5\%, pagadero a partir de abril de 2017.

\subsection{CONSIDERACIONES A PROPÓSITO DE LOS ACUERDOS DE REFINANCIACIÓN CELEBRADOS POR COOPERATIVAS}

A la vista de los tres anteriores acuerdos de refinanciación, resulta difícil hacer afirmaciones concluyentes sobre las motivaciones que han llevado a las cooperativas a celebrarlos en un momento en que las sociedades capitalistas los abandonan. Esta dificultad deriva, no sólo de la escasa muestra con la que se cuenta, sino, como ya se ha apuntado, de las constantes modificaciones de la LC que impiden valorar adecuadamente los efectos de cada reforma.

Ahora bien, sí puede señalarse alguna característica de las refinanciaciones que se han llevado a cabo. Así, la refinanciación permite la continuación de la actividad cooperativa mediante la renegociación del pasivo en términos más asequibles y facilita la entrada de dinero nuevo, con la consecuente mejora de su operatividad. De otra parte, si bien permiten liberar a los socios de realizar sacrificios económicos directos, éstos sacrificios (inherentes a la naturaleza de la cooperativa), ya sean potenciales $u$ obligados, también sirven de garantía a los acreedores financieros. Finalmente, las entidades financieras, en efecto, refuerzan las garantías para otorgar la refinanciación (como es el caso del préstamo hipotecario garantizado con aval de un Organismo público, y el mencionado compromiso de los socios cooperativistas que se obligan con su patrimonio).

En este contexto, no parece desdeñable la garantía que, para los acreedores financieros, representa una cooperativa en cuanto sociedad de base mutualista. Esta gantía debe ponerse en valor en esta sede. 


\section{Conclusiones}

1. La tradicional resistencia de las cooperativas a la crisis, basada en la finalidad para la que se constituyen, se ha visto afectada con la última gran crisis padecida en España. A partir del año 2008 comienza un debilitamiento progresivo que llega a su momento más dramático en el año 2013 para, posteriormente, iniciar su recuperación.

2. La situación privilegiada de las entidades financieras, en tiempos de crisis, agrava el efecto de encadenamiento de concursos: si los empresarios no pueden cobrar sus créditos, tampoco pueden pagar sus deudas (con especial incidencia en los autónomos, microempresas y Pymes, que representan el 99\% del tejido empresarial español). Las recientes medidas legislativas, se han dirigido a reducir la situación privilegiada de los créditos que, por regla general, ostentan las entidades bancarias con el objetivo de paliar ese efecto. Esta reducción puede haber repercutido negativamente en el mercado financiero, habiéndose reflejado en la disminución del número de acuerdos de refinanciación en en los concursos de las sociedades capitalistas.

3. Las cooperativas han mostrado el comportamiento contrario, y han recurrido a la celebración y homologación de acuerdos de refinanciación en los años 2016 y 2017. Resulta difícil hacer afirmaciones concluyentes sobre las motivaciones. Esta dificultad deriva, no sólo de la escasa muestra con la que se cuenta, sino también, de las constantes modificaciones de la Ley concursal que impiden valorar adecuadamente los efectos de cada reforma.

4. Puede, no obstante, señalarse alguna característica que se desprende de las refinanciaciones que se han llevado a cabo. Así, la refinanciación permite la continuación de la actividad cooperativa mediante la renegociación del pasivo en términos más asequibles, y facilita la entrada de dinero nuevo, con la consecuente mejora de su operatividad. De otra parte, si bien la refinanciación permite liberar a los socios de realizar sacrificios económicos directos, éstos sacrificios (inherentes al espíritu cooperativo), ya sean potenciales $u$ obligatorios, también sirven de garantía a los acreedores financieros. Finalmente, las entidades financieras sí que refuerzan las garantías para otorgar la refinanciación.

5. La garantía en conjunto que, por su propia naturaleza y finalidad, ofrece a los acreedores financieros una cooperativa, debe ponerse en valor en sede de acuerdos de refinanciación. 


\section{Bibliografía}

ATXABAL, A. 2015. "La democracia como valor identitario de la cooperativa». Cooperativismo e economía social, N. ․ 37, págs. 89-114.

AZOFRA, F. 2012. "La invulnerabilidad de los acreedores financieros con garantía real a la homologación judicial de los acuerdos de refinanciación», $R D C P$, núm. 16, págs. 127-141

CERDÁ, F.2014. "La extensión de efectos del acuerdo de refinanciación, homologado judicialmente, a los acreedores financieros disidentes o no partícipes», $A D C 0$, núm. 33, págs. 143-165;

CERVERA, $M$,

- 2014. «El procedimiento de homologación de acuerdos de refinanciación», ADCo, núm. 33, págs. 111-123.

- 2012. "Procedimiento de solicitud de homologación judicial de acuerdo preconcursal de refinanciación (Comentario al auto del juzgado mercantil n. ${ }^{\circ} 6$ de Barcelona de 5 de junio de 2012)», La Ley, n. ${ }^{\circ} 17$, págs. 195 y ss.

DIVAR, J.

- 1987. Régimen jurídico de las Sociedades Cooperativas. Universidad de Deusto.

- 2013. "Las cooperativas: una alternativa económica y social frente a la crisis». Boletín de la Asociación Internacional de Derecho Cooperativo, núm. 47, págs. 257-264.

- 2010. "Las cooperativas ante la crisis económica». Boletín de la Asociación Internacional de Derecho Cooperativo, núm. 44, págs. 195-219.

- 2009. "Crisis económica, cooperativismo e innovación». Boletín de la Asociación Internacional de Derecho Cooperativo, núm. 43, págs. 200 y ss.

FERNÁNDEZ TORRES, I. 2010. «Algunas consideraciones en torno a la refinanciación de deuda y la posibilidad de no presentar declaración de concurso (A propósito del auto del Juzgado de Primera Instancia n..$^{\circ} 9$ y Mercantil de Córdoba de 10 de septiembre de 2009», RCP, núm. 12, págs. 257-269.

GADEA, E.

- 2001. Derecho de las cooperativas, Universidad de Deusto.

- 2014. "Ley 6/2013, de Cooperativas de Cantabria: contenido y oportunidad para el desarrollo de la economía social», Deusto Estudios Cooperativos, núm. 5, págs. 155-174.

- 2012. "Delimitación del concepto de cooperativa: de los principios cooperativos a la responsabilidad social corporativa», CIRIEC - España. Revista jurídica de economía social y cooperativa, núm. 23, págs. 37-58.

- 2009. «Estudio sobre el Concepto de Cooperativa: referencia a los Principios Cooperativos y a su discutida vigencia», Jado: boletín de la Academia Vasca de Derecho, núm. 17, págs. 165-185.

GADEA, E., Atxabal, A. Izquierdo, M. E. (Coord.). 2014. Las cooperativas como alternativa económica, una visión de México y España, Dykinson.

GARCÍA-CRUCES, J.A. (dr.). 2013. Los acuerdos de refinanciación y de reestructuración de la empresa en crisis: autonomía de la voluntad e insolvencia empresarial. Bosch. 
GARCÍA-ROSTÁN, G. 2013. «Impugnación de la homologación del acuerdo de refinanciación», Los acuerdos de refinanciación y de reestructuración de la empresa en crisis: autonomía de la voluntad e insolvencia empresarial, Bosch, págs. 483-494.

GARCÍA VICENTE, J.R. 2013. "Deberes en la negociación y responsabilidad precontractual» en Los acuerdos de refinanciación y de reestructuración de la empresa en crisis: autonomía de la voluntad e insolvencia empresarial, Bosch, págs. 67-91.

GOUVEIA, Rodrigo. 2009. «Combatir la crisis económica global con la cooperación del consumidor», en Cuadernos de Economía Social, núm. 3, CEPES, Madrid, págs. 6 y ss.

FERNÁNDEZ RODRÍGUEZ, A. 2015. "El nuevo concepto del «sacrificio desproporcionado» y sus implicaciones», $R D C P$, núm. 22, págs. 241-249.

HERNANDO, G. 2009. "La crisis económica y su impacto en el marco de las relaciones laborales: la respuesta de las cooperativas como tercera vía». Boletín de Estudios Económicos, núm. 196, 179-197.

LÓPEZ SÁNCHEZ, J., 2013. «El procedimiento de homologación de acuerdos de refinanciación», Los acuerdos de refinanciación y de reestructuración de la empresa en crisis: autonomía de la voluntad e insolvencia empresarial, Bosch, págs. 293-318.

LINDE DE CASTRO, I. 2015. «Prólogo», Presente y Futuro del Mercado Hipotecario y Ley de Segunda Oportunidad para Consumidores/as y Empresarios/ as, (Dir. Sánchez Ruiz De Valdivia, I, y Olmedo Cardente, M.), Edit. Aranzadi, págs. 35-40.

MAROTO, J.A. 2015. «Rasgos (preocupantes) de la financiación bancaria a las empresas industriales». Registradores, núm. 72, pág. 45.

MARTÍNEZ CHARTERINA, A.

- 2012. "Sobre el principio de cooperación entre cooperativas en la actualidad». Boletín de la Asociación Internacional de Derecho Cooperativo, núm. 46 (Ejemplar dedicado a: Las cooperativas construyen un mundo mejor), págs. 133-146.

- 2010. "Las cooperativas frente a la crisis». Boletín de la Asociación Internacional de Derecho Cooperativo, núm. 44, págs. 195-219.

MOYA, J., 2009. "Los acuerdos de refinanciación de la nueva disposición adicional cuarta de la Ley Concursal», Revista Aranzadi Doctrinal, núm. 8.

PULGAR, J. 2009. «Estrategias preconcursales y refinanciaciones de deuda: escudos protectores en el marco del RDL/2009», Implicaciones financieras de la ley concursal: adaptado al real decreto-ley 3/2009, de 27 de marzo / coord. por Alonso, Pulgar, págs. 49-134.

QUIJANO, J. 2015. "La homologación judicial de los acuerdos de refinanciación», Estudios jurídicos en memoria del profesor Emilio Beltrán, tirant lo Blanch, Valencia, págs. 1512-1538.

SÁNCHEZ-CALERO, J. 2009. "Refinanciación y reintegración concursal» Refinanciación y reintegración concursal, eprints.ucm.es/9658/1/Refinanciaconcursal.pdf. 
SÁNCHEZ PACHÓN, L.A. 2016. «Instrumentos alternativos de financiación para las cooperativas españolas». REVESCO. Revista de Estudios Cooperativos, núm. 122, págs. 285-313.

SÁNCHEZ RUIZ DE VALDIVIA, I. 2015. "Crisis económica y Mercado Único Hipotecario: transparencia, ineficacia y segunda oportunidad para consumidores/as y empresarios/as (autónomos, microempresas y Pymes)», Presente y Futuro del Mercado Hipotecario y Ley de Segunda Oportunidad para Consumidores/as y Empresarios/as, (Dir. Sánchez Ruiz De Valdivia, I, y Olmedo Cardente, M.), Edit. Aranzadi, págs. 41-86.

SANCHO, I. 2015. «Homologación, eficacia, impugnación y rescisión de los acuerdos de refinanciación», en Díaz Moreno - León Sanz (drs.), Acuerdos de Refinanciación, Convenio y Reestructuración, Aranzadi, Cizur Menor (Navarra), págs. 145-181.

SENÉS, M. C. 2013. "La homologación de los acuerdos de refinanciación», ADCo, núm. 30, págs. 47-74.

VALPUESTA, E.,

- 2011. "Los acuerdos de refinanciación en el proyecto de reforma de la Ley Concursal», Revista de Derecho Concursal y Paraconcursal, núm. 15, págs. 155-165.

- 2009. "Comentario al art. 84 LC» en Comentarios a la Ley Concursal, Cordón (dir.), Vol.I, Edit. Aranzadi, 2.ed., págs. 943-971.

VAQUER, F. J. 2015. "La homologación judicial de acuerdos de refinanciación tras la Ley 17/2014, de 30 de septiembre», RDCP, núm. 22, págs. 223240.

ZIN, R.A. 2017. "La fusión de las cooperativas: las expectativas de gestión relacionadas con los indicadores financieros». REVESCO. Revista de Estudios Cooperativos, núm. 125, págs. 243-259. 


\section{Derechos de autor}

El Boletín de la Asociación Internacional de Derecho Cooperativo es una revista de acceso abierto lo que significa que es de libre acceso en su integridad inmediatamente después de la publicación de cada número. Se permite su lectura, la búsqueda, descarga, distribución y reutilización legal en cualquier tipo de soporte sólo para fines no comerciales y según lo previsto por la ley; sin la previa autorización de la Editorial (Universidad de Deusto) o el autor, siempre que la obra original sea debidamente citada (número, año, páginas y DOI si procede) y cualquier cambio en el original esté claramente indicado.

\section{Copyright}

The International Association of Cooperative Law Journal is an Open Access journal which means that it is free for full and immediate access, reading, search, download, distribution, and lawful reuse in any medium only for non-commercial purposes, without prior permission from the Publisher or the author; provided the original work is properly cited and any changes to the original are clearly indicated. 